\title{
Influence of Marangoni Convection on Magnetohydrodynamic Viscous Dissipation and Heat Transfer on Hybrid Nanofluids in a Rotating System among Two Surfaces
}

\author{
Ali Rehman and Zabidin Salleh *D
}

check for

updates

Citation: Rehman, A.; Salleh, Z. Influence of Marangoni Convection on Magnetohydrodynamic Viscous Dissipation and Heat Transfer on Hybrid Nanofluids in a Rotating System among Two Surfaces. Mathematics 2021, 9, 2242. https://doi.org/10.3390/ math9182242

Academic Editor: Marco Pedroni

Received: 11 July 2021

Accepted: 7 September 2021

Published: 12 September 2021

Publisher's Note: MDPI stays neutral with regard to jurisdictional claims in published maps and institutional affiliations.

Copyright: (c) 2021 by the authors. Licensee MDPI, Basel, Switzerland. This article is an open access article distributed under the terms and conditions of the Creative Commons Attribution (CC BY) license (https:// creativecommons.org/licenses/by/ $4.0 /)$.
Department of Mathematics, Faculty of Ocean Engineering Technology and Informatics, Universiti Malaysia Terengganu, Kuala Nerus 21030, Terengganu, Malaysia; alirehmanchd8@gmail.com * Correspondence: zabidin@umt.edu.my

\begin{abstract}
The present research paper explains the influence of Marangoni convection on magnetohydrodynamic viscous dissipation and heat transfer on hybrid nanofluids in a rotating system among two surfaces. Then, the properties of heat and mass transfer are analysed. With the similarity transformation, the governing equations of the defined flow problem are converted into nonlinear ordinary differential equations. These compact equations are solved approximately and analytically using the optimal homotopy analysis method. The impact of different parameters is interpreted through graphs in the form of velocity and temperature profiles. The influence of the skin friction coefficient and Nusselt number are presented in the form of tables. The comparison of the present research paper and published works is also presented table.
\end{abstract}

Keywords: hybrid nanofluids; rotating surface; MHD; viscous dissipation; BVP 2.0 package

\section{Introduction}

Single-coated two-dimensional sheets of graphite are called graphene. Due to poor solubility, graphene is mostly used as a nanofluid. It is used in the form of graphene oxide (GO) due to its highly oxidised structure. GO is used in industrial machinery and many engineering apparatus, and its flow is used for the stability of centrifugal forces by engaging the circular pressure gradient. Heat transfer is one of the important properties in chemical processes. The heat transfer properties of the base fluid, such as water and mineral oil, are different methods used to increase the heat transfer. For instance, reduced heat transfer and time heat exchanger size can be minimised. Ethylene glycol (EG) can be used as cooling fluid and anti-freezing agent to improve thermal properties because the thermal conductivity of metals and nonmetals and carbon structures are higher than those of the base fluids. Many studies have been conducted on nanofluids, but hybrid nanofluids, which are one of the new types of nanofluid, have recently attracted the attention of researchers. Hybrid nanofluids are produced in two forms: First, two or more types of nanofluids are suspended in the base fluid. Second, nanoparticles are suspended in the base fluid, such as composites. Researchers' attention on this topic can be attributed to the heat transfer rate enhancement and production cost reduction that can be achieved through the application of these nanofluids. This new type of heat transport fluid has also encouraged various researchers to study real-world problems. Moreover, hybrid nanofluids increase thermophysical properties and the heat transfer ratio. Hybrid nanofluids are subclasses of nanoliquids. They consist of two different nanoparticles sprinkled in a base fluid. They are characterised by high heat transfer ratios relative to conventional nanofluids, hence the current interest shown by the academic and industrial research communities. Specifically, researchers have taken interest in the magneto Marangoni convection of nanofluids due to its vast applications in chemical, industrial, process, thin liquid films and crystal growth. The convection is produced due to the surface tension known as Marangoni convection. 
Pop et al. [1] studied different structures of the thermo-solutal boundary film Marangoni convective method. Moreover, Al-Mudhaf and Chamkha [2] used a solute gradient to study Marangoni convection in porous media. Moreover, Wang [3] used a perturbation method to investigate Marangoni convection and thin-film spray, and Chen [4] investigated the power-law model of Marangoni convection and thin-film spray. Apart from that, Magyari and Chamkha [5] studied the impact of Reynolds number on Marangoni convection using the flow assumption. In addition, Lin et al. [6,7] used a thermal gradient to study the magnetic hydrodynamic Marangoni convective, and Aly and Ebaid [8] studied the exact solution of the Marangoni convection flow of viscid nanoliquid on a porous surface. Finally, Rehman et al. [9] analytically studied Marangoni convection on thin films using a stretching cylinder.

Nanofluids are defined as the colloidal combination of a nanosized particle $(<100 \mathrm{~nm})$ in the base fluid, and they are used to increase the heat transfer ratio of the base fluid. Due to this property, nanofluids have some key applications in industry, such as heat exchange, coolants, lubricants and microchannel heat sinks. Nanofluids are used to determine the best thermal properties with the least possible $(1 \%)$ volume fraction of the nanoparticle. Moreover, Rehman et al. [10] used a stretching surface to analytically study a unsteady thin-film nanofluid. Rehman et al. [11] used a stretching surface to analytically study an unsteady thin film along with the magnetic field. Moreover, Sandeep et al. [12] used a magnetic field to discuss the thermal enhancement of an unsteady nanofluid, and Khan et al. [13] investigated the impact of carbon nanotube (CNT) nanofluids using Riga plates. Sheikholeslami [14] used Darcy's law to discuss copper oxide-water nanofluids, and Sheikholeslami and Vajravelu [15] used variable magnetic fields to discuss the nanofluid heat transfer in a cavity. Furthermore, Aman et al. [16] used Poiseuille flow to study the variation of a thermal field, and Khan et al. [17] used a rotating conduit to discuss a threedimensional (3D) squeezed flow. The heat transfer ratio of a nanofluid is greater than that of conventional fluids, such as water, EG and oil. Recently, a new type of nanofluid known as a hybrid nanofluid was used to increase the heat transfer ratio. A hybrid nanofluid is the mixture of two or more different nanoparticles distributed in a base fluid. Many research works have been conducted to investigate thermal conductivity, revealing several dynamic declarations of these properties. For example, Han et al. [18] used temperatures between $10{ }^{\circ} \mathrm{C}$ and $90{ }^{\circ} \mathrm{C}$ to discuss a hybrid CNT. Meanwhile, Suresh et al. [19] used volume concentrations from $0.1 \%$ to $2 \%$ to discuss a $\mathrm{Al}_{2} \mathrm{O}_{3}-\mathrm{Cu} / \mathrm{H}_{2} \mathrm{O}$ hybrid nanofluid. Moreover, Madhesh and Kalaiselvam [20] examined a $\mathrm{Cu}-\mathrm{TiO}_{2}$ water base nanofluid and showed that the enhancement of the heat transfer is approximately $48.4 \%$ for a concentration of $0.7 \%$. Furthermore, Devi and Devi $[21,22]$ used a stretching sheet to study the problems of heat transfer and flow of hydromagnetic hybrid nanofluids $\left(\mathrm{Cu}-\mathrm{Al}_{2} \mathrm{O}_{3} / \mathrm{H}_{2} \mathrm{O}\right)$. By contrast, Tayebi et al. [23] numerically interpreted the problem of heat transfer analyses of $\mathrm{Cu}-\mathrm{Al}_{2} \mathrm{O}_{3} / \mathrm{H}_{2} \mathrm{O}$ hybrid nanofluids in an annulus. The characteristics of the $\mathrm{TiO}_{2}-\mathrm{Cu} / \mathrm{H}_{2} \mathrm{O}$ hybrid nanofluid with Lorentz force were analysed by Ghadikolaei et al. [24]. Meanwhile, Hayat et al. [25] studied $\mathrm{Ag}-\mathrm{CuO} /$ water hybrid nanofluids using rotating surfaces. In addition, Yousefi et al. [26] investigated the aqueous titania-copper hybrid nanofluid stagnation point flow toward the stretching cylinder. Consequently, Subhani and Nadeem [27] studied the behaviour of a $\mathrm{Cu}-\mathrm{TiO}_{2} / \mathrm{H}_{2} \mathrm{O}$ hybrid nanofluid over a stretching surface. Based on the literature study, the number of researchers working on hybrid nanofluids is very low. Thus, the purpose of the present paper was to study the effect of Marangoni convection on the combined effect of magnetohydrodynamic viscous dissipation and heat transfer on hybrid nanofluids in a rotating system among two surfaces. The approximate analytical method, namely, the optimal homotopy analysis method (OHAM), is used to solve nonlinear differential equations. Liao [28] used this method to solve the nonlinear differential equation. The results of important parameters, such as the magnetic parameter, Prandtl number, Eckert number and Marangoni convection parameters, for the velocity and temperature profiles are plotted and discussed. The convergences of the flow problem are obtained with up to 25 iterations using the BVPh 2.0 package of Mathematica. The skin friction coefficient 
and Nusselt number are explained in table form. The remainder of the paper is presented as follows: The literature review is presented in Section 1. The mathematical formulation of the important equation with boundary condition is derived in Section 2, and the results and discussion are described in Section 3. Moreover, the conclusion is presented in Section 4. The following structures define the novelty of this investigation:

- Hybrid nanofluid along with the magnetic field

- Effect of Marangoni convection on hybrid nanofluids along with the magnetic field and viscous dissipation

- Approximate analytical method [29-36] for the approximate analytical series solution of the flow problem

- Influence of Marangoni convection on the 3D flow.

\section{Mathematical Formulation of the Given Flow Problem}

Consider an incompressible time-independent viscous hybrid nanofluid between two parallel surfaces. In this combination of surfaces, one surface is stretchable, and the other is stationary. In this system, the plate and hybrid nanofluid rotate simultaneously around the $y$-axis, the $x$ is equivalent to the plate's surface, and the $z$-axis is normal to $x, y$, as shown in Figure 1 . The plates are set at $y=0$ and $y=h$. The penetrable surface of the channel is at $y=h$, which depicts the unbroken suction and injection and the movable surface of the channel at $y=0$. We also consider the influence of the constant magnetic field of strength $B_{0}$, which is normal to the plate from the $y$-axis.

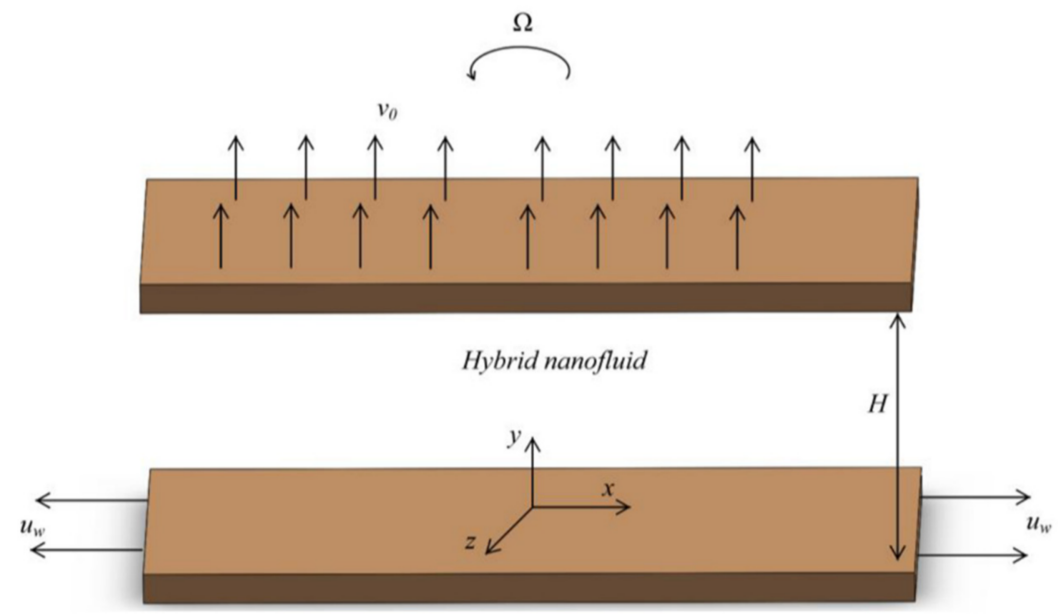

Figure 1. Geometry of the given flow problem.

The governing equations for continuity, momentum and temperature for the timeindependent 3D flow of hybrid nanofluid are given below:

$$
\begin{gathered}
\frac{\partial u}{\partial x}+\frac{\partial v}{\partial y}+\frac{\partial w}{\partial z}=0 \\
u \frac{\partial v}{\partial x}+v \frac{\partial v}{\partial y}=-\frac{1}{\rho_{h n f}} \frac{\partial p}{\partial y}+\frac{\mu_{h n f}}{\rho_{h n f}}\left(\frac{\partial^{2} v}{\partial x^{2}}+\frac{\partial^{2} v}{\partial y^{2}}\right) \\
u \frac{\partial w}{\partial x}+v \frac{\partial w}{\partial y}-2 \Omega w=\frac{\mu_{h n f}}{\rho_{h n f}}\left(\frac{\partial^{2} w}{\partial x^{2}}+\frac{\partial^{2} w}{\partial y^{2}}\right)-\frac{\sigma_{f} B_{0}^{2}}{\rho_{h n f}} w
\end{gathered}
$$

$$
u \frac{\partial T}{\partial x}+v \frac{\partial T}{\partial y}+w \frac{\partial T}{\partial z}=\frac{k_{h n f}}{\left(\rho C_{p}\right)_{h n f}}\left(\frac{\partial^{2} T}{\partial x^{2}}+\frac{\partial^{2} T}{\partial y^{2}}+\frac{\partial^{2} T}{\partial z^{2}}\right)-\frac{\sigma_{f} B_{0}^{2}}{\rho_{h n f}} u+\frac{\sigma_{f} B_{0}^{2}}{\left(\rho C_{p}\right)_{h n f}}\left(u^{2}+w^{2}\right)+\frac{\mu_{h n f}}{\left(\rho C_{p}\right)_{h n f}}\left(\frac{\partial u}{\partial y}\right)^{2}
$$


In the above equations, $u, v, w$ represent the velocity along $x, y$ and $z$-directions, respectively. $\Omega$ represents the portend angular velocity, $B_{0}$ shows the magnetic field, $B_{0}$ represents the pressure, $\sigma_{f}$ represents the electric conductivity of the nanofluid, $T$ is the temperature, and $q_{r a d}=-\left(\frac{4 \sigma^{*}}{3 k_{h n f}^{*}}\right) \frac{\partial T^{4}}{\partial y}$. is the heat flux for radiation.

The relative boundary conditions are

$$
\begin{gathered}
u=u_{w}=a x, w=0, v=0, T=T_{H} \text { at } y=0 \\
=0, w=0, v=v_{0}, T=T_{0} \text { at } y=h .
\end{gathered}
$$

The defined similarity transformations are

$$
\begin{gathered}
\eta=\frac{y}{h}, v=-a h f(\eta), u=a x f^{\prime}(\eta) \\
w=\operatorname{axg}(\eta), \theta=\frac{T-T_{H}}{T_{0}-T_{H}} .
\end{gathered}
$$

We used the approximate analytical method because it is difficult to solve nonlinear partial differential equations analytically. Thus, first, we convert nonlinear partial differential equations to nonlinear ordinary differential equations with a single independent variable $\eta$. For this, $v=-a h f(\eta), u=a x f^{\prime}(\eta), w=\operatorname{axg}(\eta)$ and $\theta=\frac{T-T_{H}}{T_{0}-T_{H}}$, from Equation (6) are substituted into Equations (1)-(4). Equation (6) satisfies Equation (1) identically. Next, we converted Equations (2)-(4) to the following forms:

$$
\begin{gathered}
g^{\prime \prime}+A_{1}(1-\phi G O-E G-\phi G O-W)^{2.5} \operatorname{Re}\left(f g^{\prime}-f^{\prime} g\right)+ \\
2 A_{1} R_{0}(1-\phi G O-E G-\phi G O-W)^{2.5} f^{\prime}-M(1-\phi G O-E G-\phi G O-W)^{2.5} g=0 . \\
f^{(i v)}+A_{1}(1-\phi G O-E G-\phi G O-W)^{2.5} \operatorname{Re} m\left(f f^{\prime \prime \prime}-f^{\prime} f^{\prime \prime}\right)- \\
2 A_{1} R_{0}(1-\phi G O-E G-\phi G O-W)^{2.5} g^{\prime}-M(1-\phi G O-E G-\phi G O-W)^{2.5} f^{\prime \prime}=0 . \\
\theta^{\prime \prime}+A_{2} \operatorname{Pr} \operatorname{Re}\left(\frac{3}{3+4 N}\right) \frac{k_{f}}{k_{h n f}} f \theta^{\prime}+\operatorname{MnPrEc}\left(\frac{3}{3+4 N}\right) \frac{k_{f}}{k_{h n f}}\left(f^{\prime 2}+g^{2}\right)=0 .
\end{gathered}
$$

where $A_{1}$ and $A_{2}$ are constantly given by

$$
\begin{gathered}
A_{1}=1-\phi G O-E G-\phi G O-W+\frac{\phi G O-E G \rho G O-E G+\phi G O-W \rho G O-W}{\rho f} \\
A_{2}=1-\phi G O-E G-\phi G O-W+\frac{\phi G O-E G\left(\rho C_{p}\right)_{G O-E G}+\phi G O-W\left(\rho C_{p}\right)_{G O-W}}{\left(\rho C_{p}\right)_{f}} .
\end{gathered}
$$

The transformed boundary conditions are given by

$$
\begin{gathered}
f(0)=0, f(1)=A, f^{\prime}(0)=1, f^{\prime}(1)=0, \\
g(1)=0, g(0)=0, \\
\theta(0)=1, \theta(1)=0 .
\end{gathered}
$$

The Prandtl number, rotation parameter, Reynolds number, magnetic parameter, radiation parameter Eckert number and suction parameter are denoted by $\operatorname{Pr}, R_{0}, R e, M n, N, E c, m$ and $A$, respectively, and the Marangoni convection parameter is $m=\frac{\gamma \sigma_{0} T_{r e f}}{\mu_{f}\left(b v_{f}\right)^{\frac{1}{2}}}$. When $A>0$, the flow is an injection, and $A<0$ implies a suction flow.

\subsection{Method of Solution}

Equations (8)-(10) are solved analytically using the OHAM given below:

$$
L(u(x))+N(u(x))+g(x)=0, B(u(x))=0
$$


where $L$ is a linear operator, $x$ is the independent variable, $g(x)$ is the unknown function, $N$ is the nonlinear operator and $B(u)$ is a boundary operator. We first determine a family of equations using this method (12):

The initial guess for the velocity and temperature is

$$
\begin{gathered}
f_{0}(\eta)=\eta^{4}-A+e^{-\eta} \\
\theta_{0}(\eta)=\frac{1}{2} e^{-\eta R} \\
g_{0}(\eta)=\frac{1}{2} e^{-\eta}
\end{gathered}
$$

which are calculated from the linear operator given below:

$$
L_{f}=f^{(i v)}+f^{\prime \prime}=0, L_{g}=g^{\prime \prime}=0, L_{\theta}=\theta^{\prime \prime}=0 .
$$

Liao [28] presented this method to identify the residual error, so Equations (7)-(9) can be written as

$$
\begin{gathered}
\varepsilon_{m}^{f}=\frac{1}{n_{1}+1} \sum_{j_{1}=1}^{n_{1}}\left[\kappa_{f}\left(\sum_{j_{1}=1}^{n_{1}} f_{1}(\eta)_{\eta=j \delta \eta}\right)\right], \\
\varepsilon_{m}^{g}=\frac{1}{n_{1}+1} \sum_{j_{1}=1}^{n_{1}}\left[\kappa_{f}\left(\sum_{j_{1}=1}^{n_{1}} g_{1}(\eta)_{\eta=j \delta \eta}\right)\right], \\
\varepsilon_{m}^{\theta}=\frac{1}{n+1} \sum_{j=1}^{n}\left[\kappa_{\theta}\left(\sum_{j=1}^{n} f(\eta)_{\eta=j \delta \eta^{\prime}} \sum_{j=1}^{n} \theta(\eta)_{\eta=j \delta \eta}\right)\right], \\
\varepsilon_{m}^{t}=\varepsilon_{m}^{f}+\varepsilon_{m}^{\theta}+\varepsilon_{m}^{g} .
\end{gathered}
$$

\subsection{Analysis of $O H A M$}

This approach is usually applied to solve boundary value functional equations. Consider the following boundary value functional equation,

$$
\begin{gathered}
L(f(\eta))+g(\eta)+N(f(\eta))=0, \\
B\left(f, \frac{d f}{d \eta}\right)=0,
\end{gathered}
$$

where $L$ and $N$ are the linear and nonlinear operators, respectively, $g(\eta)$ is a known function, $f(\eta)$ is an unknown function, and $B$ is the boundary operator. Consider the following deformation equation, given by

$$
\begin{gathered}
(1-p)[L(f(\eta, p))+g(\eta)]=H(p)[L(f(\eta, p))+g(\eta)+N(f(\eta, p))] \\
B\left(f(\eta, p), \frac{d f(\eta, p)}{d \eta}\right)
\end{gathered}
$$

where $p \in[0,1]$ is an embedding parameter and $H(p)$ for $p \neq 0$ is a non-zero auxiliary function, such that $H(p)=1$ for $p=0$ and $p=1$.

We also have $f(\eta, 0)=f_{0}(\eta)$ and $f(\eta, 1)=f(\eta)$. Thus, as $p$ increases from 0 to 1 , the solution $f(\eta, p)$ varies from $f_{0}(\eta)$ to $f(\eta)$, where $f_{0}(\eta)$ is an initial guess that satisfies the linear operator, which is obtained from Equation (14) for $p=0$. This condition yields

$$
\begin{gathered}
L\left(f_{0}(\eta)\right)+f(\eta)=0, \\
B\left(f_{0}, \frac{d f_{0}}{d \eta}\right) .
\end{gathered}
$$

The auxiliary function $H(p)$ is considered in the following power series in $p$ :

$$
H(p)=C_{1} p+C_{2} p^{2}+\cdots
$$


where $C_{1}$ and $C_{2}$ are constants to be determined. The approximate analytical solution is given by

$$
f\left(\eta, p, C_{1}, \ldots, C_{m}\right)
$$

It is usually a power series on $p$ as follows:

$$
f\left(\eta, p, C_{1}, \ldots, C_{m}\right)=f_{0}(\eta)+\sum_{k \geq 1} f_{k}\left(\eta, p, C_{1}, \ldots, C_{m}\right) p^{k}
$$

Substituting Equation (23) in Equation (24) and equating the coefficients of the terms with the identical power of $p$ lead to the governing equation $f_{0}(\eta), f_{1}(\eta)$ up to $f_{k}(\eta)$, which begins from Equation (23) given by

$$
\begin{gathered}
L\left(f_{1}(\eta)\right)=C_{1} N_{0}\left(f_{0}(\eta)\right), \\
B\left(f_{1}, \frac{d f_{1}}{d \eta}\right)=0,
\end{gathered}
$$

$$
\begin{gathered}
L\left(f_{k}(\eta)-f_{k-1}(\eta)\right)=C_{k} N_{0}\left(f_{0}(\eta)\right)+\sum_{i=1}^{k-1} C_{i}\left[L\left(f_{k-1}(\eta)+N_{k-1}\left(f_{0}(\eta), f_{1}(\eta), \ldots, f_{k-1}(\eta)\right)\right)\right] \\
B\left(f_{k}, \frac{d f_{k}}{d \eta}\right)=0, k=2,3, \ldots
\end{gathered}
$$

where $N_{m}\left(f_{0}(\eta), f_{1}(\eta), \ldots, f_{m}(\eta)\right)$ are the coefficients of $p^{m}$ obtained by expanding $N\left(f\left(\eta, p, C_{1}, \ldots, C_{m}\right)\right)$ in a power series concerning the embedding parameter $p$. Moreover,

$$
N\left(f\left(\eta, p, C_{1}, \ldots, C_{m}\right)\right)=N\left(f_{0}(\eta)+\sum_{k \geq 1} N_{k}\left(f_{0}(\eta), f_{1}(\eta), \ldots, f_{k}(\eta)\right) p^{k}\right)
$$

where $N\left(f\left(\eta, p, C_{1}, \ldots, C_{m}\right)\right)$ is given in Equation (28), where the convergence of Equation (28) depends on the auxiliary constant $C_{i}, i=1,2,3, \ldots$ If Equation (29) converges when $p=1$, one obtains

$$
f\left(\eta, C_{1}, C_{2}, \ldots, C_{m}\right)=f_{0}(\eta)+\sum_{k \geq 1} f_{k}\left(\eta, C_{1}, C_{2}, \ldots\right) .
$$

Then, the $m$-th-order approximation is then given by

$$
f\left(\eta, C_{1}, C_{2}, \ldots, C_{m}\right)=f_{0}(\eta)+\sum_{k \geq 1}^{m} f_{k}\left(\eta, C_{1}, C_{2}, \ldots, C_{m}\right) .
$$

The result for the residual is defined as

$$
R\left(\eta, C_{1}, C_{2}, \ldots, C_{m}\right)=L\left(f\left(\eta, C_{1}, C_{2}, \ldots, C_{m}\right)+f(\eta)+N\left(f\left(\eta, C_{1}, C_{2}, \ldots, C_{m}\right)\right)\right)
$$

If $\left(\eta, C_{1}, C_{2}, \ldots, C_{m}\right)=0$, then $f\left(\eta, C_{1}, C_{2}, \ldots, C_{m}\right)$ will be an exact solution, which, in general, does not happen, especially in nonlinear problems. To determine the optimal value of $C_{i}, i=1,2, \ldots, m$, we apply the least square method.

$$
\frac{\partial J}{\partial C_{1}}=\frac{\partial J}{\partial C_{2}}=\cdots=\frac{\partial J}{\partial C_{m}}=0,
$$

where

$$
J\left(C_{1}, C_{2}, \ldots, C_{m}\right)=\int_{a}^{b} R^{2}\left(\eta, C_{1}, C_{2}, \ldots, C_{m}\right) d \eta
$$

Here, the closed interval $[a, b]$ supports the given problem. Knowing these constants, the approximate solution of order $m$ can be easily determined. 


\section{Results and Discussion}

The main objective of this section is to study the nature of the approximate analytical solution of the given flow problem and the influence of different model factors, such as suction parameter $A$, magnetic field parameter $M$, rotation parameter $R_{0}$, Marangoni convection parameter $m$, Prandtl number $P r$, Reynolds number $R e$ and Eckert number $E c$, on the velocity and temperature distribution. Two sorts of hybrid nanofluids $G O-E G+G O-W$ and $G O-W$ have been used for heat enhancement applications. In this combination, $G O-W$ is the base fluid, and $G O-E G+G O-W$ represents a hybrid nanofluid. The thermophysical properties of the hybrid nanofluid have been used for the experimental data available in the literature. The flow analysis is settled over a rotating surface in a magnetic field and viscous dissipation. The approximate analytical method, i.e., OHAM, is used for the approximate analytical solution. The convergence of the OHAM for particular problems is also discussed. Moreover, the series solution for velocity and temperature profiles are calculated using OHAM. The obtained results are highlighted in Figures 2-13. Figures 2-10 portray the effects of different parameters on the velocity profile, and Figures 11-13 show the effects of different parameters on the temperature profile. Furthermore, Tables 1 and 2 represent the comparison of the present approximate analytical method and integral method from the literature. In Tables 1 and 2, $m$ represents the number of iterations. In Tables 3 and 4 , the numerical results illustrate the influences of dissimilar model factors on the skin friction coefficient and Nusselt number of $G O-E G+G O-W$ and $G O-W$. The influence of different parameters on the local skin friction coefficient is presented in Table 3. The table shows that the skin friction coefficient decreases in the cases of $G O-W$ and $G O-E G+G O-W$ for the increasing values of the suction parameter $A$ and Reynolds number Re. Meanwhile, by increasing these parameters, viscous forces decrease. As a result, the skin friction coefficient decreases. Table 4 shows the Nusselt number coefficient effect on $G O-E G+G O-W$ and $G O-W$ for the rising magnitude of Eckert number $E c$ and magnetic field parameter $M$. The Nusselt number coefficient increases in both cases of Eckert number $E c$ and magnetic field parameter $M$ on $G O-W$ and $G O-E G+G O-W$. The convergence of the hybrid nanofluid and base fluid is obtained up to the 25th iteration for the $G O-W$ and $G O-E G+G O-W$ nanofluid in Tables 5 and 6 . Tables 5 and 6 show that increasing the number of iterations reduces the residual error and strong convergence attained. Moreover, Tables 7 and 8 represent the compression of the present skin friction and Nusselt number with the literature. Figure 1 shows the geometry of the given flow problem, and Figure 2 shows the influence of the suction parameter on the velocity in the $x$ direction. In Figure 2, the velocity profile initially increases by increasing the suction parameter, but this effect is limited due to Marangoni convection. This effect changes, and after some intervals, the velocity profile decreases by increasing the suction parameter. Figure 3 shows the suction parameter's influence on the velocity profile in the $y$-direction, indicating that the velocity profile is the increasing function of the suction parameter. That is, the increasing value of the suction parameter increases the velocity distribution. Figure 4 shows the influence of the Reynolds number on velocity in the $x$ direction. In Figure 4, the velocity profile initially increases by increasing the Reynolds number, but this effect is limited due to Marangoni convection. This effect changes, and after some intervals, the velocity profile decreases by increasing the Reynolds number. Figure 5 shows the influence of the Reynolds number on the velocity profile in the $y$ direction. The velocity profile is the increasing function of the Reynolds number. That is, the increasing value of the Reynolds number increases the velocity distribution. Moreover, Figure 6 shows the influence of the magnetic field parameter on the velocity in the $x$ direction. The velocity profile initially decreases by increasing the magnetic field parameter, but this effect is limited due to the Marangoni convection. This effect changes, and after some intervals, the velocity profile increases by increasing the magnetic field parameter. Figure 7 shows the influence of the magnetic field parameter on the velocity profile in the $y$ direction. The velocity profile is the decreasing function of the magnetic field parameter. That is, the increasing value of the magnetic field parameter decreases the velocity distribution. 
Moreover, Figure 8 shows the influence of the Marangoni convection parameter in the $x$ direction. The Marangoni convection parameter shows a double effect on the velocity profile. Initially, the velocity profile decreases by increasing the Marangoni convection parameter, but this effect is limited due to the Marangoni convection. This effect changes, and after some intervals, the velocity profile increases by increasing the Marangoni convection parameter. Furthermore, Figure 9 shows the influence of the rotation parameter on the velocity in the $x$ direction. In Figure 9, the velocity profile increases by increasing rotation parameters, but this effect is limited due to the Marangoni convection. This effect changes, and after some intervals, the velocity profile decreases by increasing the rotation parameter. Furthermore, Figure 10 shows the influence of rotation parameters on the velocity profile in the y direction. In Figure 10, the velocity profile is the increasing function of the rotation parameter. That is, the increasing value of the rotation parameter increases the velocity distribution. Figure 11 shows the influence of the Prandtl number on the temperature distribution. The Prandtl number has an inverse relation to the temperature distribution, in which a large Prandtl number decreases the temperature distribution. Figure 12 shows the influence of the Eckert number on the temperature distribution. The Eckert number directly relates to the temperature distribution. In other words, a large Eckert number increases the temperature distribution. This effect is due to the direct relation of the Eckert number to the kinetic energy. Moreover, Figure 13 shows the influence of the magnetic field parameter on the temperature distribution. The magnetic field parameter directly relates to the temperature distribution, that is, a large magnetic field parameter increases the temperature distribution. This effect is due to the direct relation of the magnetic field parameter to the resistance forces.

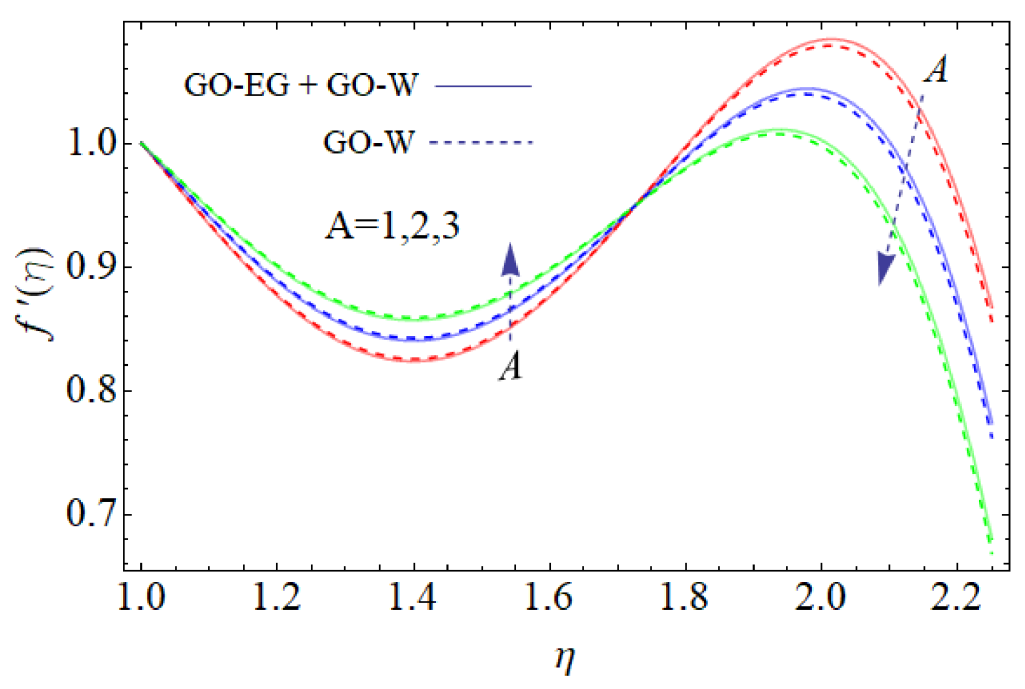

Figure 2. Influence of the injection parameter on the velocity profile. 


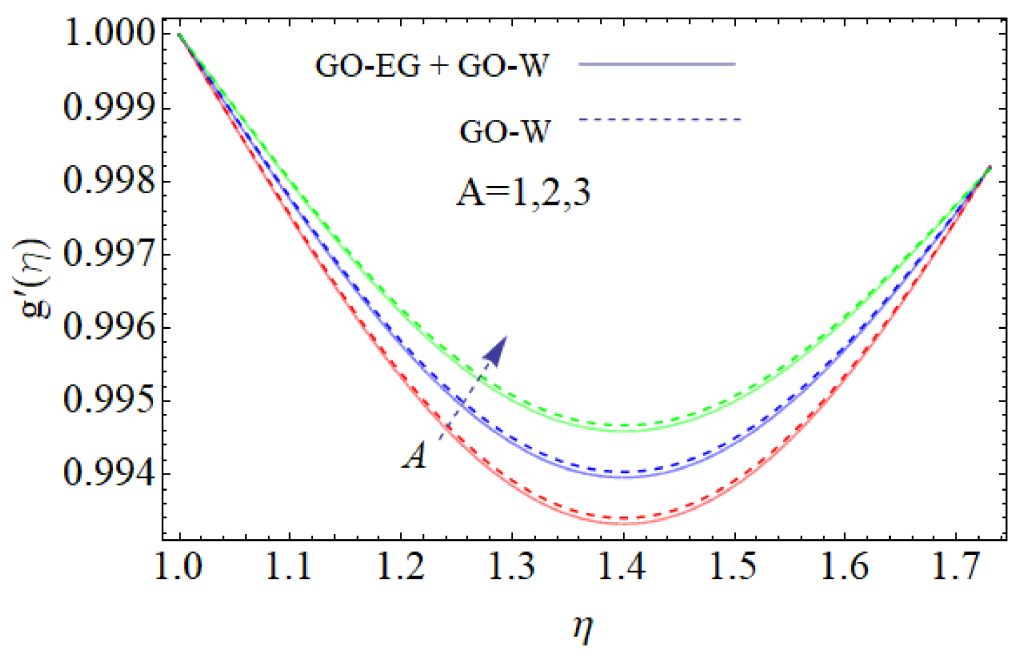

Figure 3. Influence of the injection parameter on the velocity profile.

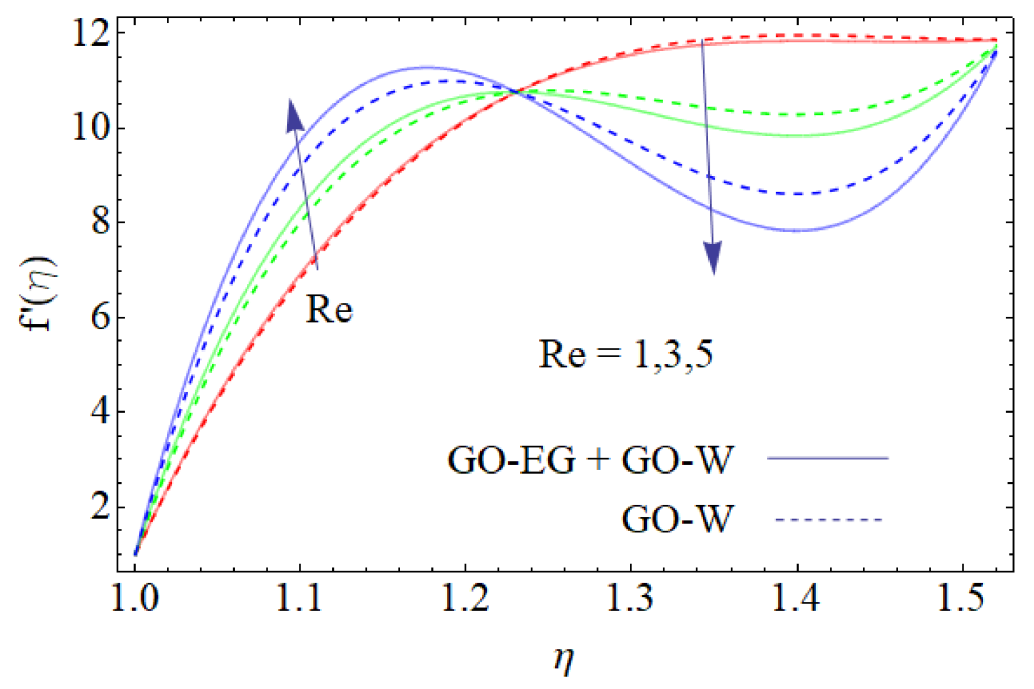

Figure 4. Influence of the Reynolds number on the velocity profile.

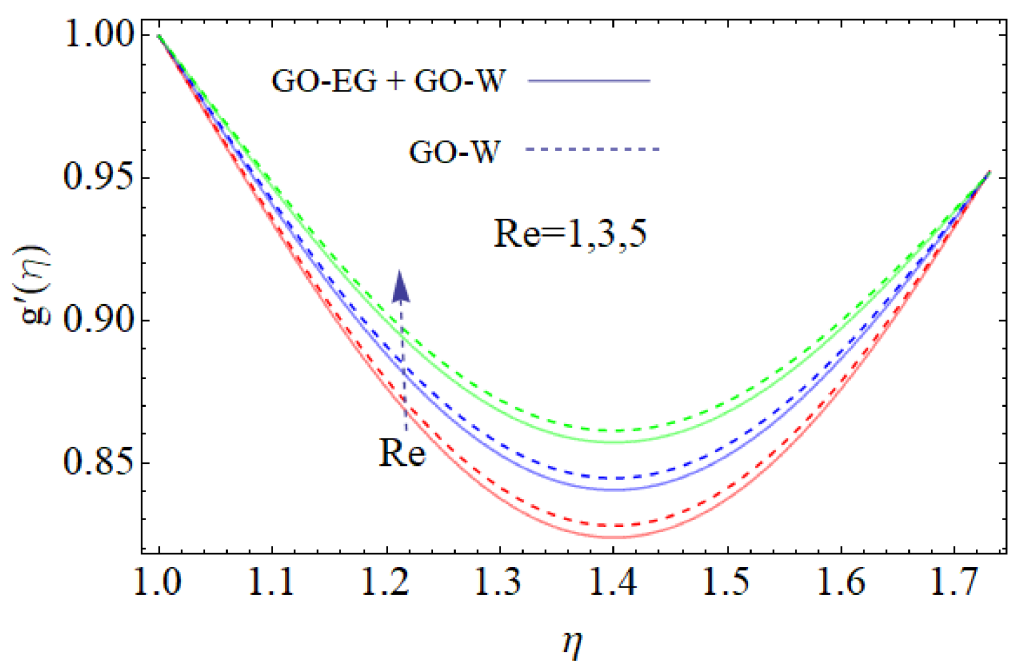

Figure 5. Influence of the Reynolds number on the velocity profile. 


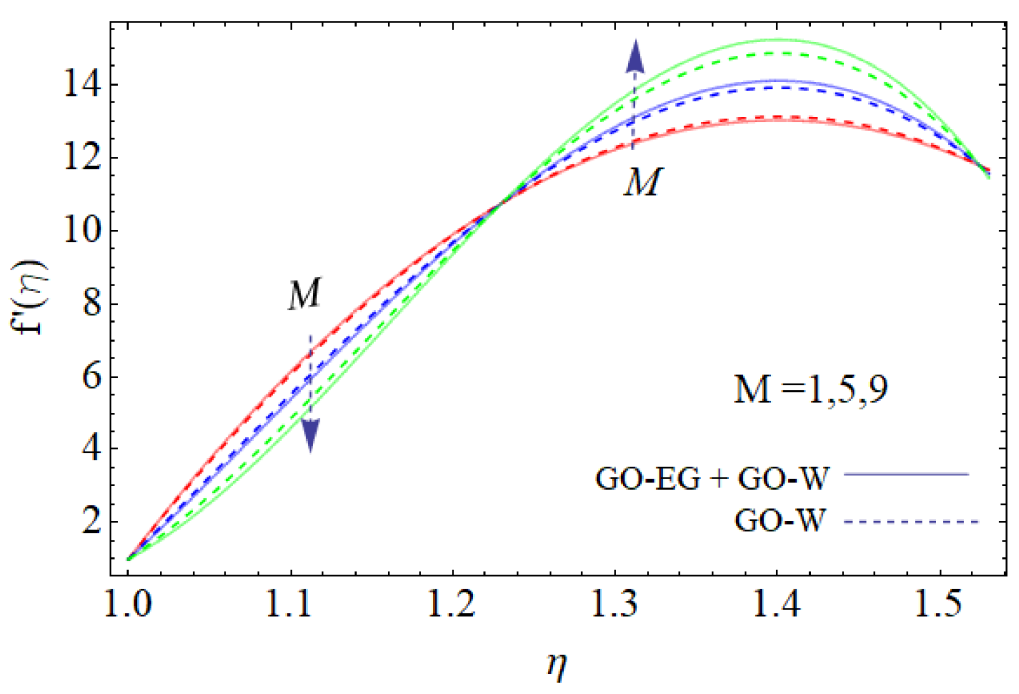

Figure 6. Influence of the magnetic field parameter on the velocity profile.

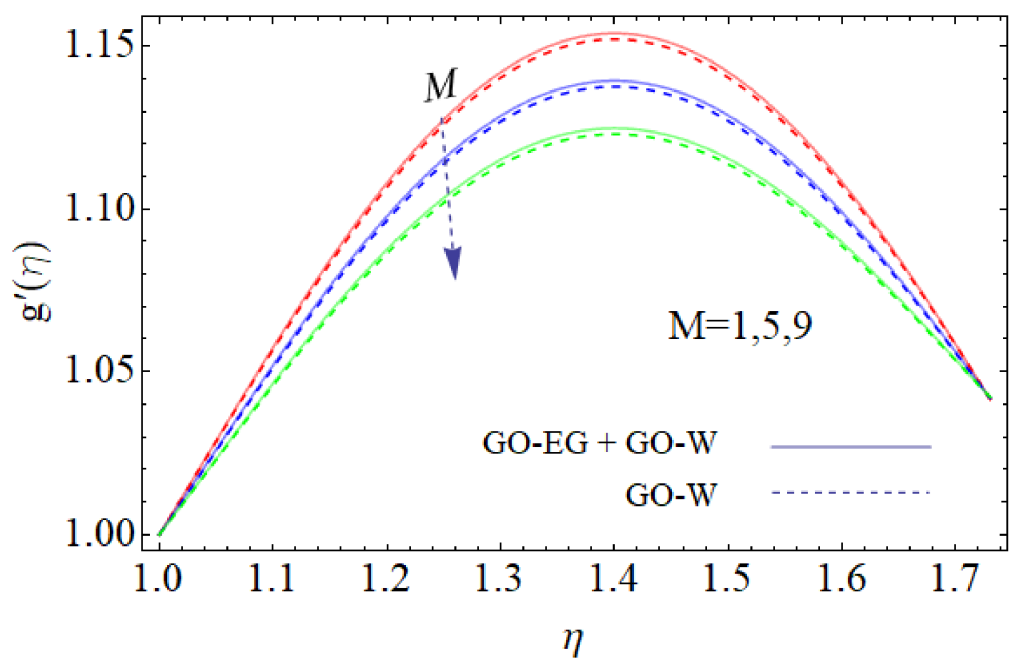

Figure 7. Influence of the magnetic field parameter on the velocity profile.

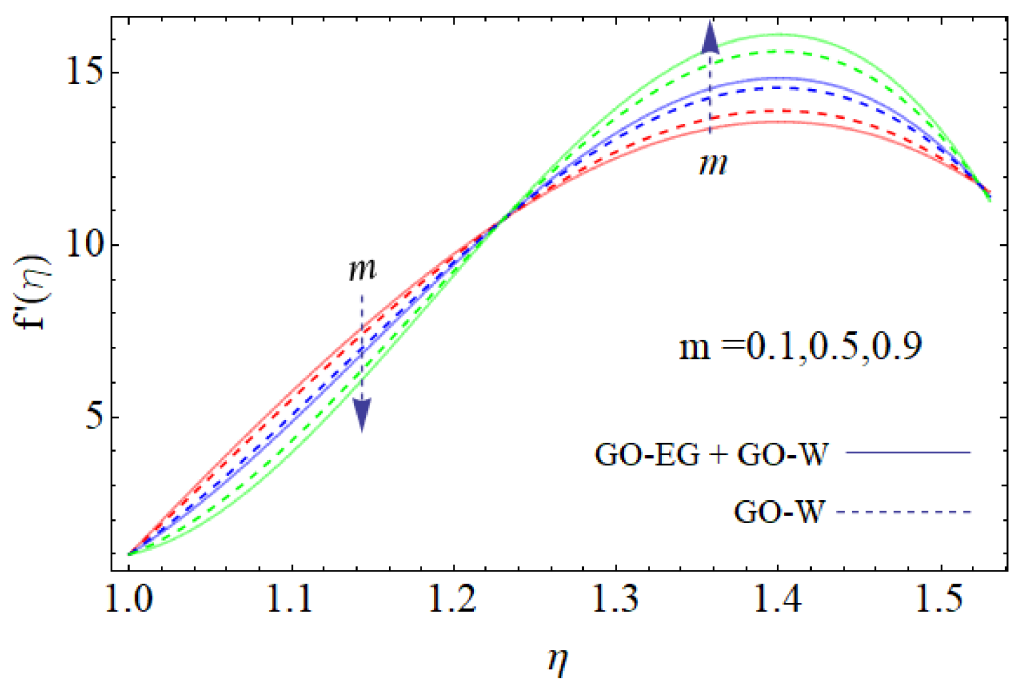

Figure 8. Influence of the Marangoni convection parameter on the velocity profile. 


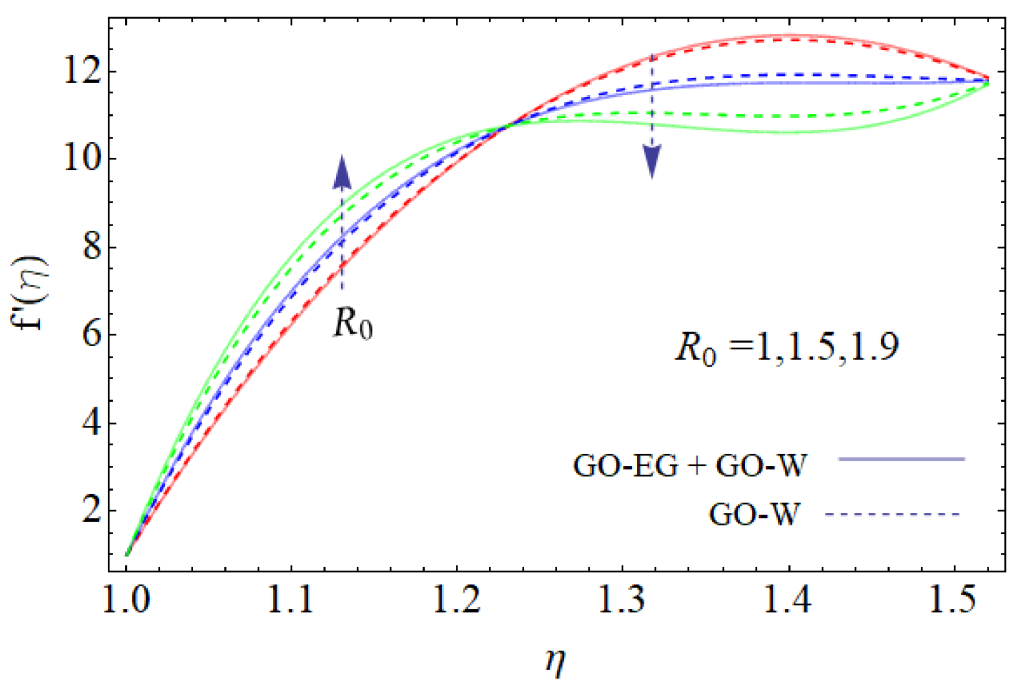

Figure 9. Influence of the rotation parameter on the velocity profile.

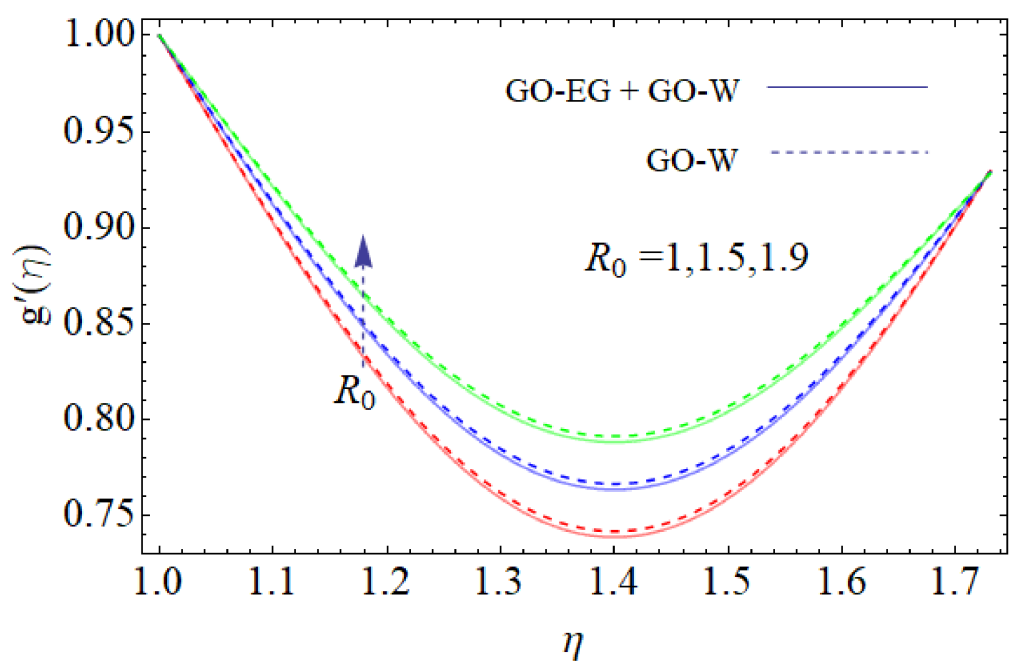

Figure 10. Influence of the rotation parameter on the velocity profile.

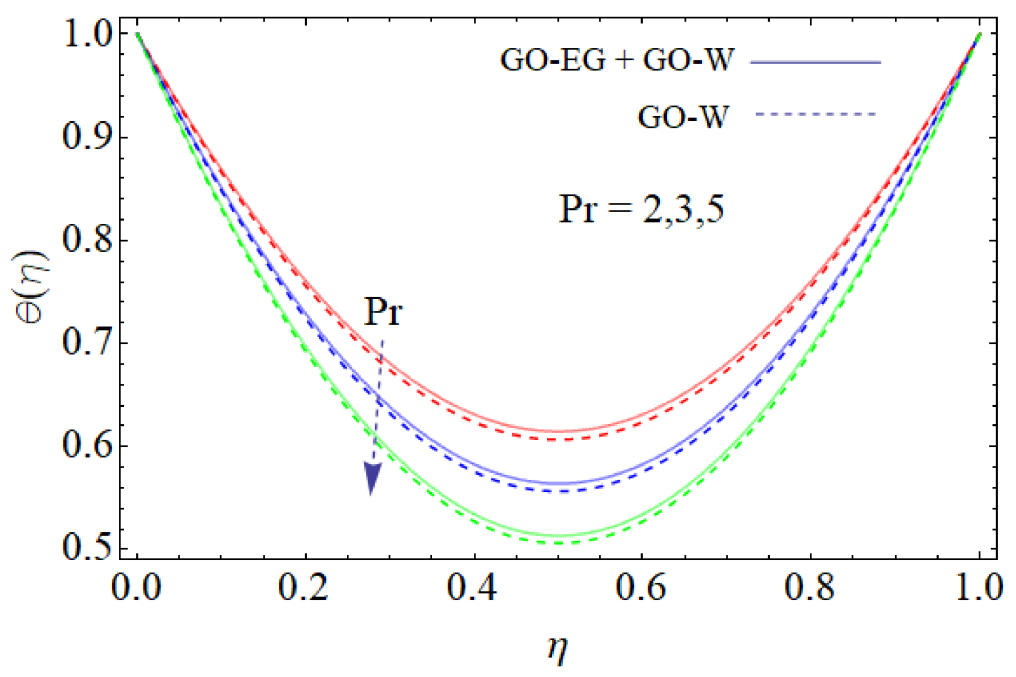

Figure 11. Influence of the Prandtl number on the temperature profile. 


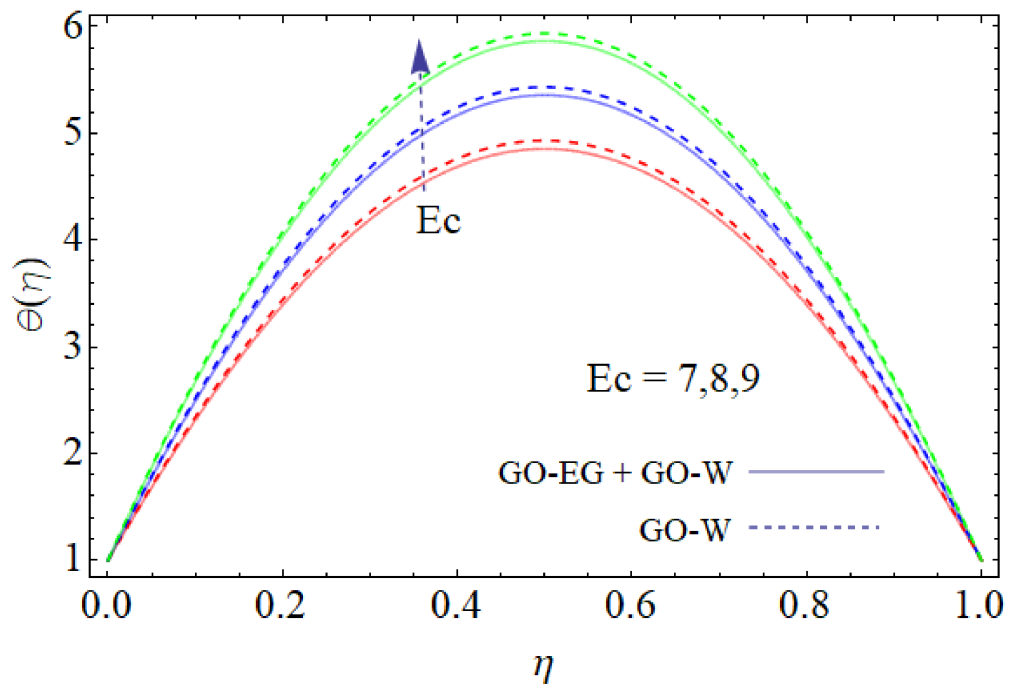

Figure 12. Influence of the Eckert number on the temperature profile.

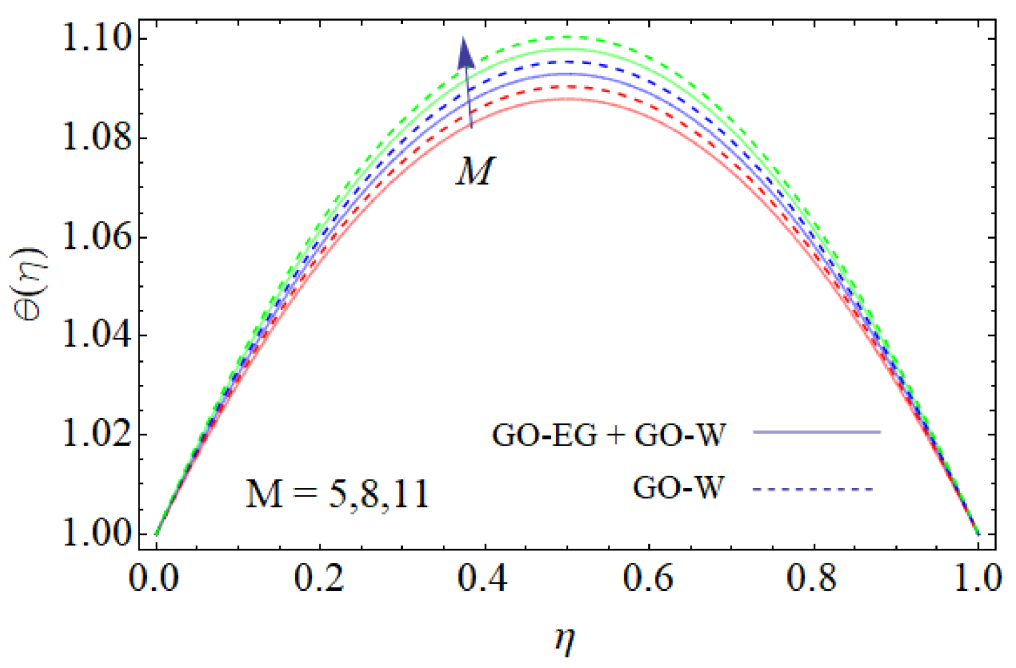

Figure 13. Influence of the magnetic field parameter on the temperature profile.

Table 1. OHAM and analytical comparison for $f(\eta)$.

\begin{tabular}{cccc}
\hline$m$ & ADM & OHAM & Absolute Error \\
\hline 1 & $1.00 \ldots$ & $1.00 \ldots$ & $7.0372 \times 10^{-12}$ \\
2 & $1.03 \ldots$ & $1.04 \ldots$ & $3.4300 \times 10^{-7}$ \\
3 & $1.03 \ldots$ & $1.04 \ldots$ & $3.2767 \times 10^{-9}$ \\
4 & $1.06 \ldots$ & $1.07 \ldots$ & $1.8614 \times 10^{-7}$ \\
5 & $0.97 \ldots$ & $0.99 \ldots$ & $1.7344 \times 10^{-8}$ \\
6 & $0.83 \ldots$ & $0.85 \ldots$ & $1.6300 \times 10^{-8}$ \\
7 & $0.73 \ldots$ & $0.76 \ldots$ & $1.7021 \times 10^{-7}$ \\
8 & $0.59 \ldots$ & $0.61 \ldots$ & $1.2500 \times 10^{-7}$ \\
9 & $0.42 \ldots$ & $0.45 \ldots$ & $2.1768 \times 10^{-9}$ \\
10 & $0.22 \ldots$ & $0.24 \ldots$ & $2.3304 \times 10^{-7}$ \\
\hline
\end{tabular}


Table 2. OHAM and numerical comparison for $\theta(\eta)$.

\begin{tabular}{cccc}
\hline$\eta$ & ADM & OHAM & Absolute Error \\
\hline 1 & $1.00 \ldots$ & $1.00 \ldots$ & $1.1102 \times 10^{-16}$ \\
2 & $1.01 \ldots$ & $1.04 \ldots$ & 0.0090 \\
3 & $1.02 \ldots$ & $1.05 \ldots$ & 0.0018 \\
4 & $1.03 \ldots$ & $1.05 \ldots$ & 0.0250 \\
5 & $1.04 \ldots$ & $1.09 \ldots$ & 0.0308 \\
6 & $1.04 \ldots$ & $1.06 \ldots$ & 0.0352 \\
7 & $1.05 \ldots$ & $1.08 \ldots$ & 0.0384 \\
8 & $1.09 \ldots$ & $1.11 \ldots$ & 0.0404 \\
9 & $1.14 \ldots$ & $1.17 \ldots$ & 0.0416 \\
10 & $1.05 \ldots$ & $1.09 \ldots$ & 0.0421 \\
\hline
\end{tabular}

Table 3. Evaluation of the suction parameter and Reynolds number on the skin friction coefficient.

\begin{tabular}{cccc}
\hline$A$ & $\boldsymbol{R} e$ & $G O-W$ & $G O-E G+G O-W$ \\
\hline 0.1000 & 0.1000 & 0.7135 & 0.9297 \\
\hline 0.2000 & 0.1500 & 0.6557 & 0.8138 \\
\hline 0.3000 & 0.2000 & 0.6111 & 0.7126 \\
\hline 0.4000 & 0.2500 & 0.5507 & 0.6114 \\
\hline 0.5000 & 0.3000 & 0.4104 & 0.5107 \\
\hline 0.6000 & 0.3500 & 0.3712 & 0.4100 \\
\hline
\end{tabular}

Table 4. Influence of the magnetic field parameter and Eckert number on Nusselt number.

\begin{tabular}{cccc}
\hline $\boldsymbol{M}$ & $E c$ & $G O-W$ & $G O-E G+G O-W$ \\
\hline 1.0000 & 0.1000 & 0.1921 & 0.1077 \\
\hline 2.0000 & 0.5000 & 0.2632 & 0.2823 \\
\hline 3.0000 & 1.0000 & 0.3743 & 0.3039 \\
\hline 4.0000 & 1.5000 & 0.4954 & 0.4564 \\
\hline 5.0000 & 2.0000 & 0.5375 & 0.6917 \\
\hline 6.0000 & 2.5000 & 0.7256 & 0.9021 \\
\hline
\end{tabular}

Table 5. Convergence of the method for $G O-E G+G O-W$.

\begin{tabular}{ccc}
\hline$m$ & $\varepsilon_{m}^{f} G O-E G+G O-W$ & $\varepsilon_{m}^{\theta} G O-E G+G O-W$ \\
\hline 5 & $0.9640 \times 10^{-1}$ & $0.8677 \times 10^{-3}$ \\
\hline 10 & $0.8809 \times 10^{-2}$ & $0.6873 \times 10^{-5}$ \\
\hline 15 & $0.7941 \times 10^{-3}$ & $0.5729 \times 10^{-7}$ \\
\hline 20 & $0.5721 \times 10^{-5}$ & $0.7410 \times 10^{-8}$ \\
\hline 25 & $0.4571 \times 10^{-7}$ & $0.5420 \times 10^{-9}$ \\
\hline
\end{tabular}

Table 6. Convergence method for $G O-W$.

\begin{tabular}{ccc}
\hline $\boldsymbol{m}$ & $\varepsilon_{m}^{f} G O-W$ & $\varepsilon_{m}^{\theta} G \boldsymbol{O}-\boldsymbol{W}$ \\
\hline 5 & $0.6719 \times 10^{-1}$ & $0.3574 \times 10^{-1}$ \\
\hline 10 & $0.6016 \times 10^{-3}$ & $0.4571 \times 10^{-2}$ \\
\hline 15 & $0.5138 \times 10^{-5}$ & $0.5159 \times 10^{-5}$ \\
\hline 20 & $0.4610 \times 10^{-6}$ & $0.5276 \times 10^{-7}$ \\
\hline 25 & $0.3301 \times 10^{-9}$ & $0.7665 \times 10^{-9}$ \\
\hline
\end{tabular}


Table 7. Comparison of the present skin friction coefficient with the past literature.

\begin{tabular}{cccc}
\hline $\boldsymbol{A}$ & $\boldsymbol{R} \boldsymbol{e}$ & Present Values & Literature Values \\
\hline 0.1000 & 0.1000 & 0.7135 & 0.6217 \\
\hline 0.2000 & 0.1500 & 0.6557 & 0.5218 \\
\hline 0.3000 & 0.2000 & 0.6111 & 0.5316 \\
\hline 0.4000 & 0.2500 & 0.5507 & 0.4274 \\
\hline 0.5000 & 0.3000 & 0.4104 & 0.3907 \\
\hline 0.6000 & 0.3500 & 0.3712 & 0.2130 \\
\hline
\end{tabular}

Table 8. Comparison of the present Nusselt number with the literature.

\begin{tabular}{cccc}
\hline $\boldsymbol{M}$ & $\boldsymbol{E c}$ & Present Values & Literature Values \\
\hline 1.0000 & 0.1000 & 0.1921 & 0.2347 \\
\hline 2.0000 & 0.5000 & 0.2632 & 0.3513 \\
\hline 3.0000 & 1.0000 & 0.3743 & 0.4133 \\
\hline 4.0000 & 1.5000 & 0.4954 & 0.5124 \\
\hline 5.0000 & 2.0000 & 0.5375 & 0.6314 \\
\hline 6.0000 & 2.5000 & 0.7256 & 0.8165 \\
\hline
\end{tabular}

\section{Conclusions}

In this research work, the influence of Marangoni convection on magnetohydrodynamic viscous dissipation and heat transfer on a hybrid nanofluid in a rotating system among two surfaces is examined. The properties of the heat and mass transfer were analysed. Applying the analytical method makes it difficult to solve nonlinear partial differential equations, so we used similarity transformation; the major partial differential equation was converted to a set of nonlinear ordinary differential equations. The approximate analytical method, i.e., OHAM, was used to determine the approximate analytical solution of the nonlinear ordinary differential equation. The impact of important parameters on the velocity and temperature profiles were plotted and discussed through graphs and tables. The skin friction coefficient and Nusselt number were explained in table form. The comparison of ADM and OHAM was presented in Tables 1 and 2, where $m$ represents the number of iterations. Finally, the obtained outputs are deliberated as follows:

1. By increasing the magnetic parameter, the velocity shows a double effect in the $x$-direction.

2. By increasing the magnetic parameter, the velocity in the $y$-direction decreases.

3. By increasing the suction parameter, the velocity shows a double effect in the $x$-direction.

4. By increasing the suction parameter, the velocity in the $y$-direction increases.

5. By increasing the rotation parameter, the velocity shows a double effect in the $x$-direction.

6. By increasing the rotation parameter, the velocity increases in the $y$-direction.

7. By increasing the Reynolds number, the velocity shows a double effect in the $x$-direction.

8. By increasing the Reynolds number, the velocity increases in the $y$-direction.

9. By increasing the Marangoni convection parameter, the velocity shows a double effect in the $x$-direction.

10. By increasing the Eckert number, the temperature profile increases.

11. By increasing the Prandtl number, the temperature profile decreases.

12. By increasing the magnetic field parameter, the temperature profile increases.

Author Contributions: Conceptualisation, A.R. and Z.S.; methodology, A.R.; software, A.R.; validation, A.R. and Z.S.; formal analysis, A.R.; writing—original draft preparation, A.R.; writing—review and editing, Z.S.; supervision, Z.S.; project administration, Z.S.; funding acquisition, Z.S. Both authors have read and agreed to the published version of the manuscript. 
Funding: This research has been partially supported by Universiti Malaysia Terengganu under the Postgraduate Research Grant (PGRG) vote no. 55193/3.

Institutional Review Board Statement: Not applicable.

Informed Consent Statement: Not applicable.

Data Availability Statement: Not applicable.

Acknowledgments: We thank Imran Khan and Taza Gul from the Bacha Khan University Charsadda, Pakistan and City University of Science and Information Technology, Pakistan, respectively, for their help and support in improving the final version of this paper.

Conflicts of Interest: The authors declare no conflict of interest.

$\begin{array}{ll}\text { Nomenclature } \\ x, y, z \quad \text { Cartesian coordinates } \\ u, v, w \quad \text { Velocity components } \\ U_{w}, V_{w} & \text { Velocities of the stretching sheet } \\ A & \text { Time injection parameter } \\ T & \text { Local temperature } \\ M & \text { Magnetic field } \\ m & \text { Marangoni convection parameter } \\ P r & \text { Prandtl number } \\ T_{w} & \text { Surface temperature } \\ B_{0} & \text { Constant magnetic field } \\ T_{\infty} & \text { Ambient temperature } \\ R e & \text { Reynolds number } \\ R_{0} & \text { Rotation parameter } \\ C_{f x} & \text { Skin friction coefficient in } x \text {-direction } \\ C_{f y} & \text { Skin friction coefficient in } y \text {-direction }\end{array}$

\section{References}

1. Pop, I.; Postelnicu, A.; Grosan, T. Thermo-solutal Marangoni forced convection boundary layers. Meccanica 2001, 36, 555-571.

2. Al-Mudhaf, A.; Chamkha, A.J. Similarity solutions for MHD thermo-solutal Marangoni convection over a flat surface in the presence of heat generation or absorption effects. Heat Mass Transf. 2005, 42, 112-121. [CrossRef]

3. Wang, C.Y. Liquid film sprayed on a stretching surface. Chem. Eng. Commun. 2006, 193, 869-878. [CrossRef]

4. Chen, C.H. Marangoni effects on forced convection of power-law liquids in a thin film over a stretching surface. Phys. Lett. A 2007, 370, 51-57. [CrossRef]

5. Magyari, E.; Chamkha, A.J. Exact analytical solutions for thermo-solutal Marangoni convection in the presence of heat and mass generation or consumption. Heat Mass Transf. 2007, 43, 965-974. [CrossRef]

6. Lin, Y.; Zheng, L.; Zhang, X. Magneto-hydrodynamics thermo-capillary Marangoni convection heat transfer of power-law fluids driven by temperature gradient. J. Heat Transf. 2013, 135, 051702. [CrossRef]

7. Lin, Y.; Zheng, L.; Zhang, X. Radiation effects on Marangoni convection flow and heat transfer in pseudo-plastic non-Newtonian nanofluids with variable thermal conductivity. Int. J. Heat Mass Transf. 2014, 77, 708-716. [CrossRef]

8. Aly, E.H.; Ebaid, A. Exact analysis for the effect of heat transfer on MHD and radiation Marangoni boundary layer nanofluid flow past a surface embedded in a porous medium. J. Mol. Liq. 2016, 215, 625-639. [CrossRef]

9. Rehman, A.; Gul, T.; Salleh, Z.; Mukhtar, S.; Hussain, F.; Nisar, K.S.; Kumam, P. Effect of the Marangoni convection in the unsteady thin film spray of CNT nanofluids. Processes 2019, 7, 392. [CrossRef]

10. Rehman, A.; Salleh, Z.; Gul, T.; Zaheer, Z. The impact of viscous dissipation on the thin film unsteady flow of GO-EG/GO-W nanofluids. Mathematics 2019, 7, 653. [CrossRef]

11. Rehman, A.; Salleh, Z.; Gul, T. The impact of the magnetic field and viscous dissipation on the thin film unsteady flow of GO-EG/GO-W nanofluids. J. Phys. Conf. Ser. 2019, 1336, 012031. [CrossRef]

12. Sandeep, N.; Sharma, R.P.; Ferdows, M. Enhanced heat transfer in unsteady magneto hydrodynamic nanofluid flow embedded with aluminum alloy nanoparticles. J. Mol. Liq. 2017, 234, 437-443. [CrossRef]

13. Ahmed, N.; Khan, A.U.; Mohyud-Din, S.T. Influence of thermal radiation and viscous dissipation on squeezed flow of water between Riga plates saturated with carbon nanotubes. Colloids Surf. A Physicochem. Eng. Asp. 2017, 522, 389-398. [CrossRef]

14. Sheikholeslami, M. CuO-water nanofluid free convection in a porous cavity considering Darcy law. Eur. Phys. J. Plus 2017, $132,55$. [CrossRef] 
15. Sheikholeslami, M.; Vajravelu, K. Nanofluid flow and heat transfer in a cavity with variable magnetic field. Appl. Math. Comput. 2017, 298, 272-282. [CrossRef]

16. Aman, S.; Khan, I.; Ismail, Z.; Salleh, M.Z. Impacts of gold nanoparticles on MHD mixed convection Poiseuille flow of nanofluid passing through a porous medium in the presence of thermal radiation, thermal diffusion and chemical reaction. Neural Comput. Appl. 2018, 30, 789-797. [CrossRef] [PubMed]

17. Khan, U.; Ahmed, N.; Mohyud-Din, S.T. Numerical investigation for three dimensional squeezing the flow of nanofluid in a rotating channel with lower stretching wall suspended by carbon nanotubes. Appl. Therm. Eng. 2017, 113, 1107-1117. [CrossRef]

18. Ahmed, H.E.; Mohammed, H.A.; Yusoff, M.Z. An overview on heat transfer augmentation using vortex generators and nanofluids: Approaches and applications. Renew. Sustain. Energy Rev. 2012, 16, 5951-5993. [CrossRef]

19. Suresh, S.; Venkitaraj, K.P.; Selvakumar, P.; Chandrasekar, M. Synthesis of $\mathrm{Al}_{2} \mathrm{O}_{3}-\mathrm{Cu}$ /water hybrid nanofluids using two step method and its thermo physical properties. Colloids Surf. A Physicochem. Eng. Asp. 2011, 388, 41-48. [CrossRef]

20. Madhesh, D.; Kalaiselvam, S. Experimental analysis of hybrid nanofluid as a coolant. Procedia Eng. 2014, 97, 1667-1675. [CrossRef]

21. Devi, S.A.; Devi, S.S.U. Numerical investigation of hydromagnetic hybrid $\mathrm{Cu}-\mathrm{Al}_{2} \mathrm{O}_{3} /$ water nanofluid flow over a permeable stretching sheet with suction. Int. J. Nonlinear Sci. Numer. Simul. 2016, 17, 249-257. [CrossRef]

22. Devi, S.U.; Devi, S.A. Heat transfer enhancement of $\mathrm{Cu}-\mathrm{Al}_{2} \mathrm{O}_{3} /$ water hybrid nanofluid flow over a stretching sheet. J. Niger. Math. Soc. 2017, 36, 419-433.

23. Tayebi, T.; Chamkha, A.J. Free convection enhancement in an annulus between horizontal confocal elliptical cylinders using hybrid nanofluids. Numer. Heat Transf. Part A Appl. 2016, 70, 1141-1156. [CrossRef]

24. Ghadikolaei, S.S.; Yassari, M.; Sadeghi, H.; Hosseinzadeh, K.; Ganji, D.D. Investigation on thermophysical properties of TiO ${ }_{2}-$ $\mathrm{Cu} / \mathrm{H}_{2} \mathrm{O}$ hybrid nanofluid transport dependent on shape factor in MHD stagnation point flow. Powder Technol. 2017, 322, 428-438. [CrossRef]

25. Hayat, T.; Nadeem, S.; Khan, A.U. Rotating flow of Ag-CuO/ $\mathrm{H}_{2} \mathrm{O}$ hybrid nanofluid with radiation and partial slip boundary effects. Eur. Phys. J. E 2018, 41, 75. [CrossRef] [PubMed]

26. Yousefi, M.; Dinarvand, S.; Yazdi, M.E.; Pop, I. Stagnation-point flow of an aqueous titania-copper hybrid nanofluid toward a wavy cylinder. Int. J. Numer. Methods Heat Fluid Flow 2018, 28, 1716-1735. [CrossRef]

27. Subhani, M.; Nadeem, S. Numerical analysis of micropolar hybrid nanofluid. Appl. Nanosci. 2019, 9, 447-459. [CrossRef]

28. Liao, S.J. An optimal homotopy-analysis approach for strongly non-linear differential equations. Commun. Nonlinear Sci. Numer. Simul. 2010, 15, 2003-2016. [CrossRef]

29. Liao, S.J. A kind of approximate solution technique which does not depend upon small parameters (II)-An application in fluid mechanics. Int. J. Non-Linear Mech. 1997, 32, 815-822. [CrossRef]

30. Liao, S.J. On the homotopy analysis method for non-linear problems. Appl. Math. Comput. 2004, 147, 499-513.

31. Liao, S.J. Homotopy Analysis Method in Non-Linear Differential Equations; Springer and Higher Education Press: Heidelberg, Germany, 2012.

32. Gul, T.; Ferdous, K. The experimental study to examine the stable dispersion of the graphene nanoparticles and to look at the GO- $\mathrm{H}_{2} \mathrm{O}$ nanofluid flow between two rotating disks. Appl. Nanosci. 2018, 8, 1711-1728. [CrossRef]

33. Gul, T.; Nasir, S.; Islam, S.; Shah, Z.; Khan, M.A. Effective Prandtl number model influences on the $\gamma \mathrm{Al}_{2} \mathrm{O}_{3}-\mathrm{AH}_{2} \mathrm{O}$ and $\gamma \mathrm{Al}_{2} \mathrm{O}_{3}-\mathrm{C}_{2} \mathrm{H}_{6} \mathrm{O}_{2}$ nanofluids spray along a stretching cylinder. Arab. J. Sci. Eng. 2019, 44, 1601-1616. [CrossRef]

34. Gohar; Gul, T.; Khan, W.; Shuaib, M.; Khan, M.A.; Bonyah, E. MWCNTs/SWCNTs nanofluid thin film flow over a nonlinear extending Disc: OHAM solution. J. Therm. Sci. 2019, 28, 115-122.

35. Gul, T.; Haleem, I.; Ullah, I.; Khan, M.A.; Bonyah, E.; Khan, I.; Shuaib, M. The study of the entropy generation in a thin film flow with variable fluid properties past over a stretching sheet. Adv. Mech. Eng. 2018, 10. [CrossRef]

36. Khan, W.; Idress, M.; Gul, T.; Khan, M.A.; Bonyah, E. Three non-Newtonian fluids flow considering thin film over an unsteady stretching surface with variable fluid properties. Adv. Mech. Eng. 2018, 10. [CrossRef] 